\title{
Análise dos Efeitos do Déficit Hídrico na Resposta Temporal do Índice de Vegetação por Diferença Normalizada (NDVI) no Estado do Amazonas
}

\author{
Analysis of the Effects of drought on Time Response of Vegetation Index Normalized \\ Difference (NDVI) in the State of Amazonas
}

\section{Célia Maria Paiva ${ }^{1}$; Alice da Silva Gonçalves de Jesus ${ }^{1}$; Gutemberg Borges França1 ${ }^{1}$, Luciana Mara Temponi Oliveira ${ }^{2}$}

\author{
${ }^{1}$ Universidade Federal do Rio de Janeiro, Rio de Janeiro, RJ, Brasil \\ celia@lma.ufrj.br, licemeteoro@gmail.com, gutemberg@lma.ufrj.br, \\ ${ }^{2}$ Fundação Instituto Brasileiro de Geografia e Estatística, Rio de Janeiro, RJ, Brasil \\ lutemponi@gmail.com
}

\begin{abstract}
Resumo
Índices de vegetação obtidos por sensoriamento remoto orbital podem auxiliar na identificação de ocorrência de secas em escala regional. O Índice de Vegetação por Diferença Normalizada (NDVI) tem sido amplamente usado no monitoramento da vegetação, com resultados promissores. Mediante tais constatações, este trabalho tem como objetivo identificar os padrões de resposta temporal do NDVI em relação à ocorrência de déficit/excedente hídrico para diferentes regiões do Bioma Amazônico, bem como compreender o ciclo sazonal e interanual desse índice. Para tanto, foram utilizados dados de cinco estações meteorológicas do Instituto Nacional de Meteorologia (INMET) e um conjunto de dados orbitais da série EFAI-NDVI com resolução temporal de 10 dias e resolução espacial de $0,1^{\circ} \times$ 0,1 $1^{\circ}$. O período estudado compreende os anos de 1982 a 1990 . Os resultados indicam que a resposta do NDVI à ocorrência de déficit hídrico é de um mês em todas as regiões. No caso do excedente hídrico, essa resposta apresenta maior variabilidade de um a quatro meses. Em relação à sazonalidade do NDVI, os maiores valores ocorrem após a estação chuvosa da região e os menores valores ocorrem após a estação seca. Quanto ao comportamento interanual, o NDVI decresce em anos de El Niño e se eleva em anos de La Niña.
\end{abstract}

Palavras-Chave: Sensoriamento remoto; Índice de vegetação; Seca

\begin{abstract}
Vegetation indices derived by remote sensing can help identify occurrence of drought on a regional scale. The Normalized Difference Vegetation Index (NDVI) has been widely used in vegetation monitoring, with promising results. This study aims to identify the patterns of temporal response of NDVI in relation to occurrence of deficit/surplus water to different regions of the Amazon biome, as well as understand its seasonal and inter-annual cycles. Therefore, data from five weather stations of the National Institute of Meteorology (INMET) and a set of orbital data of EFAI-NDVI were used. The study period covers the years 1982 to 1990. The results indicate that the response of NDVI to the occurrence of drought is one month in all regions. In the case of water surplus, that response varies from one to four months. Seasonally, the highest NDVI values occur after the rainy season in the region and the lowest values occurring after the dry season. On inter-annual behavior, the NDVI decreases in El Niño years and rises in La Niña years.
\end{abstract}




\section{Introdução}

A Floresta Amazônica tem papel de destaque por ser a maior floresta tropical do mundo. O Bioma está passando por um processo de descaracterização e desmatamento causado pelo uso e ocupação da terra, o que pode ser considerado o principal problema da região (IBGE, 2004). As principais ameaças à Amazônia hoje são: a pecuária bovina extensiva, o cultivo da soja, a produção de carvão vegetal, a exploração madeireira predatória, o modelo fundiário, o narcotráfico e a guerrilha, o tráfico de animais e plantas, a caça predatória, as obras de hidrelétricas, hidrovias e estradas, o garimpo e a pesca predatória. Com isto ocorre a destruição da biodiversidade, grandes desmatamentos e queimadas, a poluição dos rios, e o sofrimento dos povos nativos (Filho, 2006). A mudança no uso da terra pode provocar uma queda significativa na precipitação da região, uma vez que $50 \%$ da precipitação amazônica vêm da evapotranspiração das plantas (Moran, 2010). As secas severas ocorridas em 2005 e 2010 podem estar relacionadas à grande questão das mudanças globais (Marengo et al., 2011; Nobre et al., 2012). Por outro lado, já é bem conhecida a influência de eventos de El Ñino e La Ñina e do aquecimento anômalo da temperatura do Atlântico tropical na precipitação da região amazônica (Borman \& Nobre, 2013).

Índices de vegetação obtidos por sensoriamento remoto orbital podem auxiliar na identificação de ocorrência de secas em escala regional. O Índice de vegetação por Diferença Normalizada (NDVI) tem sido usado no monitoramento desse fenômeno e de seus impactos na vegetação (Almeida, 1997; Almeida \& Batista, 1998; Assad et al., 1988; Assad et al. 1996; Campos et al., 2009; Gutman, 1990; Kogan, 1990; Hutchinson, 1991; Paiva et al., 2007) com resultados promissores. Liu \& Kogan (1996) reportam que o NDVI responde com uma defasagem temporal de um mês à ocorrência de precipitação e de déficit hídrico na região norte do estado de São Paulo. Adicionalmente, mencionam que dependendo do regime de precipitação, tipo de vegetação e tipo de solo, essa resposta temporal pode variar de região para região. Consequentemente, um mesmo valor de NDVI pode estar associado à situação de seca em uma determinada região e em outra não. Assim, é importante identificar o padrão de resposta do NDVI ao déficit hídrico em cada região. Hellden \& Eklundh (1988) relataram uma correlação entre anomalias de NDVI e de ocorrência de seca severa e de escassez de chuva em diferentes regiões da Etiópia. Batista et al. (1997), utilizando dados de NDVI da Amazônia, identificaram variações interanuais associadas a mudanças nas condições ambientais. Barbosa (1998), utilizando médias mensais, constatou que as distribuição espacial e temporal da precipitação e do NDVI na região do Nordeste do Brasil, têm padrões semelhantes e uma relação considerável.

Mediante tais constatações, este estudo tem como objetivo identificar padrões de resposta temporal do NDVI em relação ao déficit e excedente hídrico na Região Amazônica, bem como investigar a influência dos fenômenos de El Niño e La Niña nesse índice.

\section{Materiais e Métodos}

Neste estudo, as áreas de interesse compreendem porções de vegetação nativa dentro de um raio de $50 \mathrm{~km}$ em relação à localização de cada uma das cinco estações meteorológicas do Instituto Nacional de Meteorologia (INMET), situadas no Estado do Amazonas, selecionadas como fontes de dados climatológicos (Figura 1). Sendo que, cada uma dessas cinco áreas correspondem a uma superfície de $3 \times 3 \mathrm{~km}$ equivalente a uma matriz de $3 \times 3$ píxeis das imagens de NDVI utilizadas neste trabalho. 


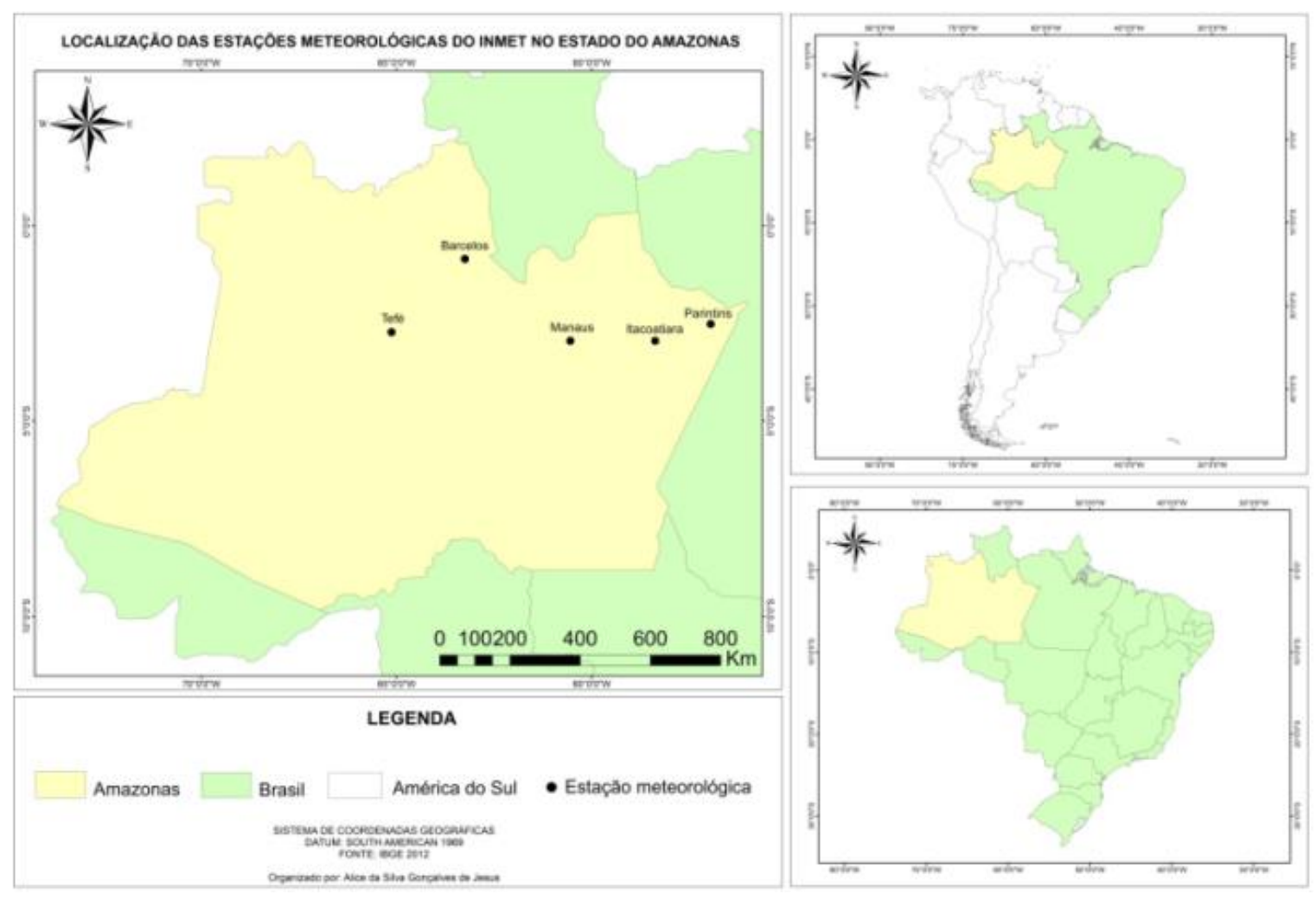

Figura 1 - Localização das estações meteorológicas do INMET no Estado do Amazonas. (Fonte: IBGE)

Os dados utilizados na elaboração do Balanço Hídrico Climatológico (BHC) compreendem uma série histórica de temperatura média mensal e precipitação total média mensal, entre os anos de 1982 e 1990, obtidos nas cinco estações meteorológicas mencionadas.

Adicionalmente foram utilizados dados da série temporal do EFAI-NDVI (European Fourier Adjusted and Interpolated Normalized Difference Vegetation Index - Índice de Vegetação por Diferença Normalizada NDVI), desenvolvido por Stöckli \& Vidale (2004) a partir do conjunto de dados do Pathfinder do NDVI NOAA/NASA (National Oceanic and Atmospheric Administration/National Aeronautics and Space Administration), referente ao período e áreas de interesse deste estudo.

O conjunto de dados do Pathfinder do NDVI da NOAA/NASA foi obtido pelo sensor AVHRR a bordo dos satélites da série NOAA (7 - 9 - 11 - 14). Este conjunto de dados foi corrigido para o espalhamento Rayleigh, absorção de ozônio, e degradação instrumental para o período que compreende os anos de 1982 a 2001, com resolução temporal de 10 dias e espacial de $0,1^{\circ}$ x $0,1^{\circ}$ (Stöckli \& Vidale, 2004; Oliveira, 2008).

A análise da resposta do NDVI em relação ao déficit e excedente hídrico, obtidos pelo BHC, foi feita para cada uma das cinco áreas de estudo e para cada ano do período considerado, conforme descrito a seguir:

i) Para cada ano da série histórica foram extraídos os valores mensais de NDVI mínimo, médio e máximo, dentro de uma janela de $3 \times 3$ píxeis, correspondente às áreas de vegetação nativa situadas em um raio de $50 \mathrm{~km}$ em relação à localização de cada uma das cinco estações meteorológicas consideradas;

ii) Para cada ano da série histórica foi calculado o BHC pelo método desenvolvimento por Thornthwaite \& Mather (1955), com os dados de temperatura média mensal e precipitação total média mensal. Deste cálculo foram extraídos os valores médios mensais de déficit e excedente hídrico para cada uma 
das cinco estações meteorológicas consideradas;

iii) Para cada ano da série histórica foi determinada a defasagem de tempo entre a ocorrência do maior déficit hídrico e o menor valor de NDVI e entre o maior excedente hídrico e o maior valor de NDVI para cada uma das cinco áreas consideradas;

iv) Para toda a série histórica foi calculado o BHC e extraídos os valores médios mensais de NDVI para cada uma das cinco áreas consideradas. Para tanto, foram geradas imagens médias mensais de NDVI para o período de 1982 a 1990.

\section{Resultados e Discussão}

\subsection{Comportamento anual do NDVI versus Balanço Hídrico Climatológico}

São apresentados na Tabela 1, os resultados obtidos a partir dos valores de deficiência hídrica máxima e NDVI mínimo e excedente hídrico máximo e NDVI máximo, bem como os meses em que estes ocorreram e a defasagem em meses entre tais ocorrências para a estação meteorológica de Barcelos do INMET. Tabelas idênticas foram elaboradas para as demais estações e seus principais resultados são apresentados a seguir. Para fins de exemplificação, somente a Tabela 1 será apresentada.

Tabela 1 - Valores de deficiência hídrica máxima, NDVI mínimo, excedente hídrico máximo, NDVI máximo, meses em que os mesmos ocorrem, defasagem em meses entre: a ocorrência de deficiência hídrica máxima e NDVI mínimo e a ocorrência de excedente hídrico máximo e NDVI máximo nos respectivos anos em que ocorreram para a estação de Barcelos do INMET

\begin{tabular}{l|c|c|c|c|c|c|c|c|c|c}
\hline Ano & $\begin{array}{c}\text { Def_- } \\
\text { Máx } \\
(\mathbf{m m})\end{array}$ & $\begin{array}{c}\text { Mês/ } \\
\text { Ano }\end{array}$ & $\begin{array}{c}\text { NDVI_ } \\
\text { Mín }^{2}\end{array}$ & $\begin{array}{c}\text { Mês/ } \\
\text { Ano }\end{array}$ & $\begin{array}{c}\text { Defasa } \\
\text { gem }\end{array}$ & $\begin{array}{c}\text { Exc_ } \\
\text { Máx } \\
\mathbf{( m m}\end{array}$ & $\begin{array}{c}\text { Mês/ } \\
\text { Ano }\end{array}$ & $\begin{array}{c}\text { NDVI_ } \\
\text { Máx }^{4}\end{array}$ & $\begin{array}{c}\text { Mês/ } \\
\text { Ano }\end{array}$ & Defasagem \\
\hline $\mathbf{1 9 8 2}$ & $-80,75$ & $11 / 82$ & 0,5696 & $02 / 83$ & 03 & 213,38 & $05 / 82$ & 0,6308 & $06 / 82$ & 01 \\
$\mathbf{1 9 8 3}$ & $-80,38$ & $02 / 83$ & 0,5897 & $03 / 83$ & 01 & 291,03 & $04 / 83$ & 0,6859 & $06 / 83$ & 02 \\
$\mathbf{1 9 8 4}$ & $-0,19$ & $10 / 84$ & 0,6649 & $11 / 84$ & 01 & 130,09 & $06 / 84$ & 0,7025 & $07 / 84$ & 01 \\
$\mathbf{1 9 8 5}$ & $-26,79$ & $09 / 85$ & 0,6220 & $10 / 85$ & 01 & 126,34 & $06 / 85$ & 0,6903 & $07 / 85$ & 01 \\
$\mathbf{1 9 8 6}$ & $-29,24$ & $08 / 86$ & 0,6229 & $10 / 86$ & 02 & 210,85 & $05 / 86$ & 0,6535 & $07 / 86$ & 02 \\
$\mathbf{1 9 8 7}$ & $-49,32$ & $10 / 87$ & 0,6264 & $11 / 87$ & 01 & 237,13 & $04 / 87$ & 0,6929 & $07 / 87$ & 03 \\
$\mathbf{1 9 8 8}$ & $-20,52$ & $10 / 88$ & 0,6457 & $11 / 88$ & 01 & 243,27 & $04 / 88$ & 0,6789 & $05 / 88$ & 01 \\
$\mathbf{1 9 8 9}$ & $-40,63$ & $12 / 89$ & 0,6413 & $03 / 90$ & 03 & 418,39 & $05 / 89$ & 0,6885 & $07 / 89$ & 02 \\
$\mathbf{1 9 9 0}$ & $-60,08$ & $10 / 90$ & - & - & - & 407,33 & $03 / 90$ & 0,7043 & $06 / 90$ & 03 \\
\hline
\end{tabular}

${ }^{1}$ Def_Máx: Deficiência Hídrica Máxima Anual;

${ }^{2}$ NDVI_Mín: NDVI Mínimo Anual;

${ }^{3}$ Exc_Máx: Excedente Hídrico Máximo Anual;

${ }^{4}$ NDVI_Máx: NDVI Máximo Anual. 
Nas Tabelas 2 e 3 são apresentados resumos dos resultados obtidos para o NDVI e o BHC nas cinco estações para o período considerado neste estudo, com base nas informações sintetizadas na Tabela 1 e tabelas idênticas elaboradas para as demais áreas, mas não apresentadas .

Durante o período de estudo, a deficiência hídrica máxima apresentou valores entre -0,19 mm em Barcelos e -166,05 mm em Itacoatiara, ocorrendo com maior frequência nos meses de agosto, outubro e novembro (Barcelos em outubro com 44\% dos casos; Itacoatiara em outubro com 33\% dos casos; Manaus em agosto e outubro, cada um com $44 \%$ dos casos; Parintins em novembro com $78 \%$ dos casos; Tefé em agosto com 37\% dos casos).

Já o NDVI mínimo variou entre 0,4864 em Itacoatiara e 0,6649 em Barcelos, ocorrendo com maior frequência nos meses de março, setembro, novembro e dezembro (Barcelos em novembro com 37\% dos casos; Itacoatiara em março e novembro, cada um com 33\% dos casos; Manaus em novembro com 33\% dos casos; Parintins em dezembro com $44 \%$ dos casos; Tefé em setembro com 37\% dos casos).

Entre a ocorrência da deficiência hídrica máxima e NDVI mínimo, há uma defasagem predominante de um mês para todas as estações (Barcelos 62\% dos casos; Itacoatiara 44\% dos casos; Manaus $44 \%$ dos casos; Parintins 66\% dos casos; Tefé 37\% dos casos).
Os valores de excedente hídrico máximo variaram entre 43,41 $\mathrm{mm}$ e 578,60 $\mathrm{mm}$, ambos em Parintins. Nota-se, que estes ocorrem em maior frequência entre os meses de fevereiro e maio (Barcelos em abril e maio, cada um com 33\% dos casos; Itacoatiara em março com 33\% dos casos; Manaus em fevereiro e março, cada um com 33\% dos casos; Parintins em abril com 56\% dos casos; Tefé em maio com 33\% dos casos).

O NDVI máximo variou entre 0,6115 em Itacoatiara e Manaus e 0,7052 em Parintins, ocorrendo em maior frequência nos meses de junho e julho (Barcelos, Itacoatiara e Parintins em julho com 56\% dos casos; Manaus em julho com 33\% dos casos; Tefé em junho com $67 \%$ dos casos).

Em relação à defasagem entre o excedente hídrico máximo e NDVI máximo existe uma variabilidade de um a quatro meses (Barcelos 2 mês com 44\% dos casos; Itacoatiara 4 meses com 33\% dos casos; Manaus de 4 meses com 33\%; Parintins de 3 meses com $44 \%$ dos casos; Tefé de 1 meses com $44 \%$ dos casos). A seguir serão apresentados os gráficos com os valores médios mensais de NDVI e do BHC para o período de 1982 a 1990 para as cinco áreas de estudo (Figuras 2A a 2E). Em geral, nas cinco estações as curvas do balanço hídrico e do NDVI apresentaram um padrão de comportamento muito semelhante, porém defasado no tempo, indicando que o NDVI responde às variações de deficiência e excedente hídrico não imediatamente, mas algum tempo depois.

Tabela 2 - Valores mínimos, medianos e máximos para: deficiência hídrica máxima, NDVI mínimo, meses em que estes ocorrem com maior frequência e defasagem em meses, para as cinco estações do

INMET consideradas neste estudo

\begin{tabular}{l|c|c|c|c|c|c|c}
\hline \multirow{2}{*}{ Estação } & \multicolumn{3}{|c|}{ DEF_Máx (mm) } & \multicolumn{3}{c|}{ NDVI_Mín } & \multirow{2}{*}{ Defasagem } \\
\cline { 2 - 7 } & Mínimo & Máximo & Mês & Mínimo & Máximo & Mês & \\
\hline Barcelos & $-0,19$ & $-80,75$ & $10(44 \%)$ & 0,5696 & 0,6649 & $11(37 \%)$ & $1(62 \%)$ \\
Itacoatiara & $-39,55$ & $-166,05$ & $10(33 \%)$ & 0,4864 & 0,6194 & 3 e $11(33 \%)$ & $1(44 \%)$ \\
Manaus & $-55,87$ & $-139,99$ & 08 e $10(44 \%)$ & 0,5179 & 0,6387 & $11(33 \%)$ & $1(44 \%)$ \\
Parintins & $-108,64$ & $-159,06$ & $11(78 \%)$ & 0,5214 & 0,6448 & $12(44 \%)$ & $1(66 \%)$ \\
Tefé & $-17,01$ & $-41,77$ & $08(37 \%)$ & 0,5214 & 0,6614 & $9(37 \%)$ & $1(37 \%)$ \\
\hline
\end{tabular}


Tabela 3 - Valores mínimos, medianos e máximos para: excedente hídrico máximo, NDVI máximo, meses em que estes ocorrem com maior frequência e defasagem em meses, para as cinco estações do

INMET consideradas no estudo

\begin{tabular}{l|c|c|c|c|c|c|c}
\hline \multirow{2}{*}{ Estação } & \multicolumn{3}{|c|}{ EXC_Máx (mm) } & \multicolumn{3}{c|}{ NDVI_Máx } & \multirow{2}{*}{ Defasagem } \\
\cline { 2 - 7 } & Mínimo & Máximo & Mês & Mínimo & Máximo & Mês & \\
\hline Barcelos & 126,34 & 418,39 & 4 e $5(33 \%)$ & 0,6308 & 0,7043 & $7(56 \%)$ & $2(44 \%)$ \\
Itacoatiara & 164,23 & 513,75 & $3(33 \%)$ & 0,6115 & 0,6929 & $7(56 \%)$ & $4(33 \%)$ \\
Manaus & 171,50 & 418,90 & 2 e 3(33\%) & 0,6115 & 0,692 & $7(33 \%)$ & $4(33 \%)$ \\
Parintins & 43,41 & 578,60 & $4(56 \%)$ & 0,6177 & 0,7052 & $7(56 \%)$ & $3(44 \%)$ \\
Tefé & 153,25 & 439,20 & $5(33 \%)$ & 0,6325 & 0,6850 & $6(67 \%)$ & $1(44 \%)$ \\
\hline
\end{tabular}

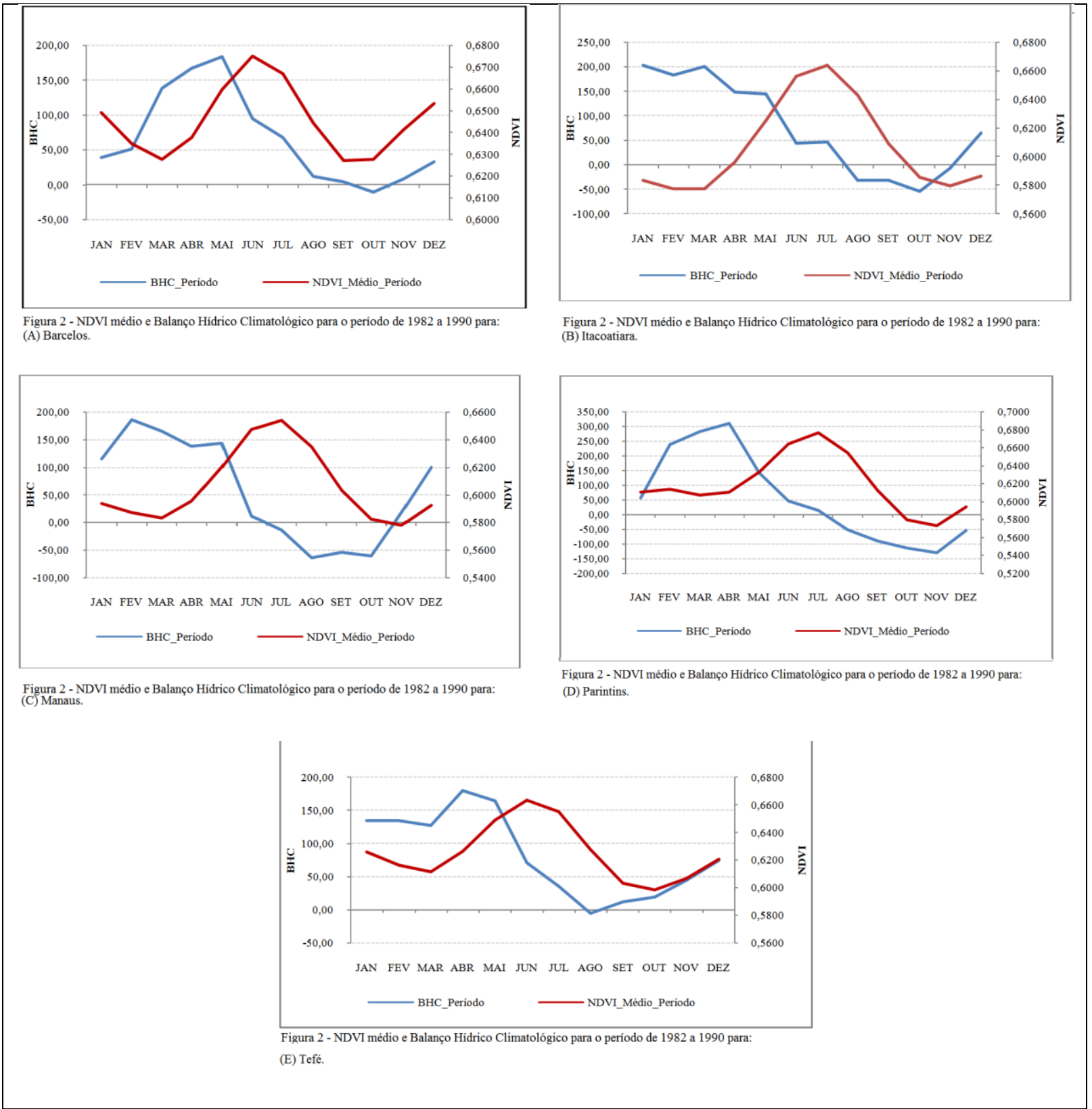

Figura 2 - NDVI Médio e Balanço Hídrico Climatológico no período de 1982 a 1990: (A) Barcelos; (B) Itacoatiara; (C) Manaus; (D) Parintins; (E) Tefé 
No caso de Barcelos, a curva do balanço hídrico apresentou um mínimo em outubro e um máximo em maio. A resposta do NDVI máximo ocorreu com uma defasagem média de um mês em relação ao excedente hídrico máximo, mas para a deficiência hídrica, essa resposta, na média, não apresentou defasagem (Figura 2A). Em Itacoatiara, pode-se observar que os valores mínimos e máximos do balanço hídrico ocorreram em outubro e março, respectivamente. Entre o excedente hídrico e o NDVI máximo, ocorreu uma defasagem média de quatro meses. Entre a deficiência hídrica máxima e o NDVI mínimo ocorreu uma defasagem média de um mês (Figura 2B). Para Manaus, a curva do balanço hídrico apresentou um mínimo em outubro e um máximo em fevereiro. O maior valor de NDVI ocorreu com uma defasagem de cinco meses em relação ao excedente hídrico. Para a deficiência hídrica a resposta do NDVI ocorreu com uma defasagem de um mês (Figura 2C). Em Parintins, a curva do balanço hídrico apresentou um mínimo em novembro e um máximo em abril. A resposta do NDVI máximo ocorreu com uma defasagem de três meses. Já para a deficiência hídrica a resposta do NDVI, em média, não apresentou defasagem (Figura 2D). Em Tefé, a curva do balanço hídrico apresentou um mínimo em agosto e um máximo em abril. Pode-se observar que tanto para o excedente quanto para a deficiência hídrica, a resposta do NDVI ocorre com uma defasagem de dois meses (Figura 2E).

\subsection{Análise interanual do NDVI}

O comportamento interanual dos valores de NDVI, nas cinco estações consideradas (Figuras de 3 a 7), respondem aos eventos de El Niño e La Niña. Esse comportamento fica bem evidenciado pelo ajuste de um polinômio de ordem seis que apresenta valores mínimos e máximos em anos de El Niño e La Niña, respectivamente. Em outras palavras, o NDVI decresce em anos de El Niño e se eleva em anos de La Niña. $\mathrm{Na}$ região de estudo, os efeitos do El Niño e La Niña refletem-se em anos mais secos e mais chuvosos respectivamente (Borman \& Nobre, 2013). Os biênios de 1982/83 e 1988/89 destacam-se por terem sido marcadamente seco e chuvoso, respectivamente, devido à ocorrência de eventos fortes de El Niño e La Niña (Borman \& Nobre, 2013). Pode-se observar que no biênio 1982/83 houve um decréscimo acentuado dos valores de NDVI com as maiores amplitudes do período de estudo. Por sua vez, o biênio 1988/89 teve as maiores elevações de NDVI e menores amplitudes. O biênio 1990/91 não pode ser observado devido à forte contaminação dos dados durante por aerossóis lançados na atmosfera pela erupção do vulcão Monte Pinatubo em 1991.

Quanto aos valores anuais de deficiência hídrica (Tabela 4), tem-se que as maiores e menores deficiências ocorreram da seguinte forma: Barcelos igual a $-252,09 \mathrm{~mm}$ em 1983 (El Niño forte) e igual a $-0,19 \mathrm{~mm}$ em 1984 (La Niña fraca), com uma amplitude de $251,90 \mathrm{~mm}(99 \%)$; Itacoatiara igual a $-432,84$ mm em 1982 (El Niño forte) e igual a $-49,20$ $\mathrm{mm}$ em 1984 (La Niña fraca), com uma amplitude de -383,64 mm (89\%); Manaus igual a -484,00 mm em 1987 (El Niño moderado) e 79,14 mm em 1989 (La Niña forte), com uma amplitude de $-404,86 \mathrm{~mm}$ (84\%); Parintins igual a -836,36 mm em 1983 (El Niño forte) e 308,86 mm em 1989 (La Niña forte), com uma amplitude de $-527,50 \mathrm{~mm}$ (63\%); e Tefé igual a -128,35 mm em 1983 (El Niño forte) e 0,00 mm em 1985 (La Niña fraca), com uma amplitude de $-128,35 \mathrm{~mm}$ (83\%). A maior amplitude ocorreu em Parintins e a menor em Tefé. Todos os maiores valores de deficiência hídrica anual ocorreram em anos de El Niño (forte ou moderado). Os menores valores ocorreram em anos de La Niña (fraca ou forte). 


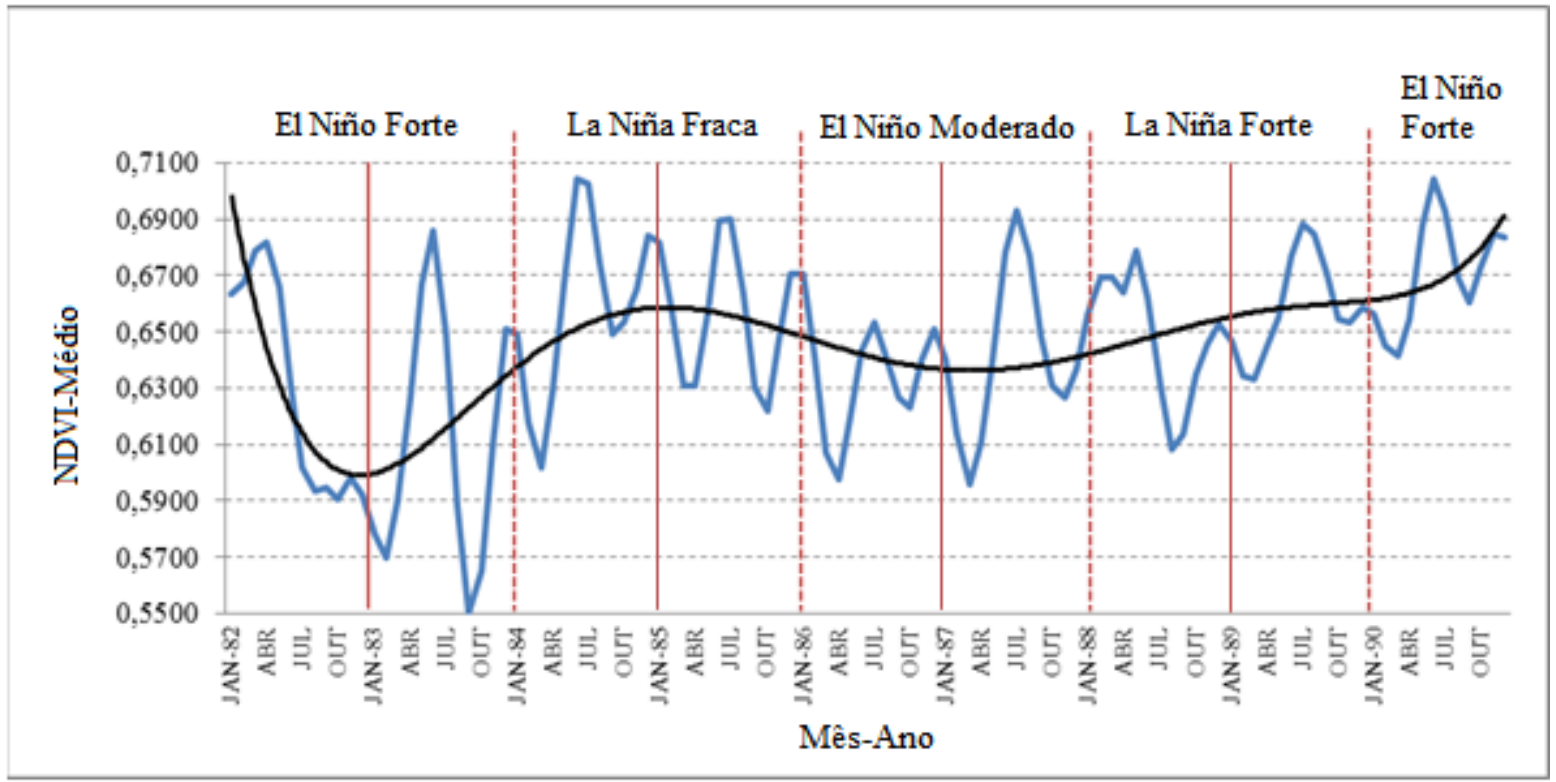

Figura 3 - NDVI médio para Barcelos e eventos de El Niño e La Niña, no periodo de 1982 a 1990.

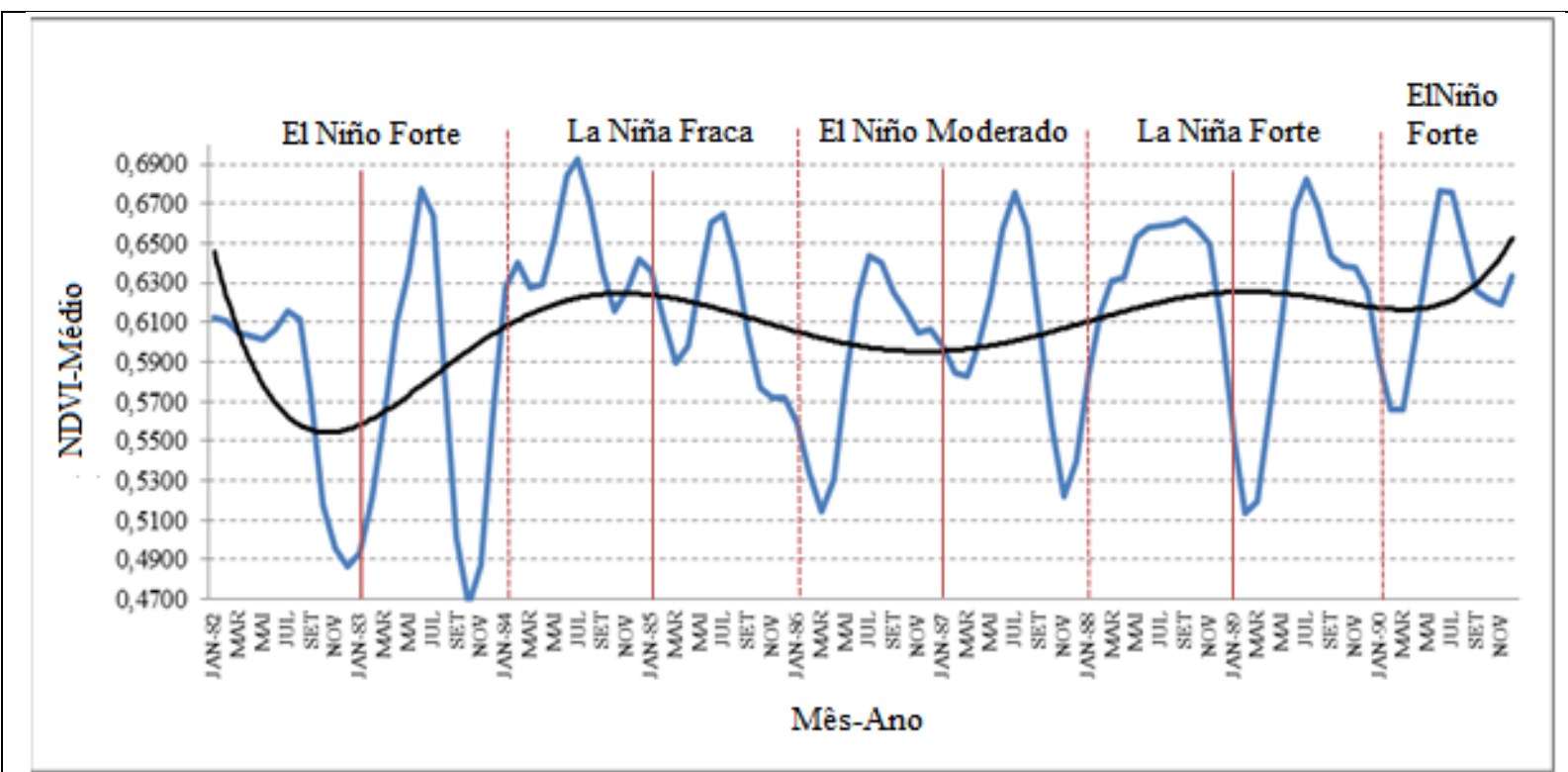

Figura 4 - NDVI médio para Itacoatiara e eventos de El Niño e La Niña, no periodo de 1982 a 1990 . 


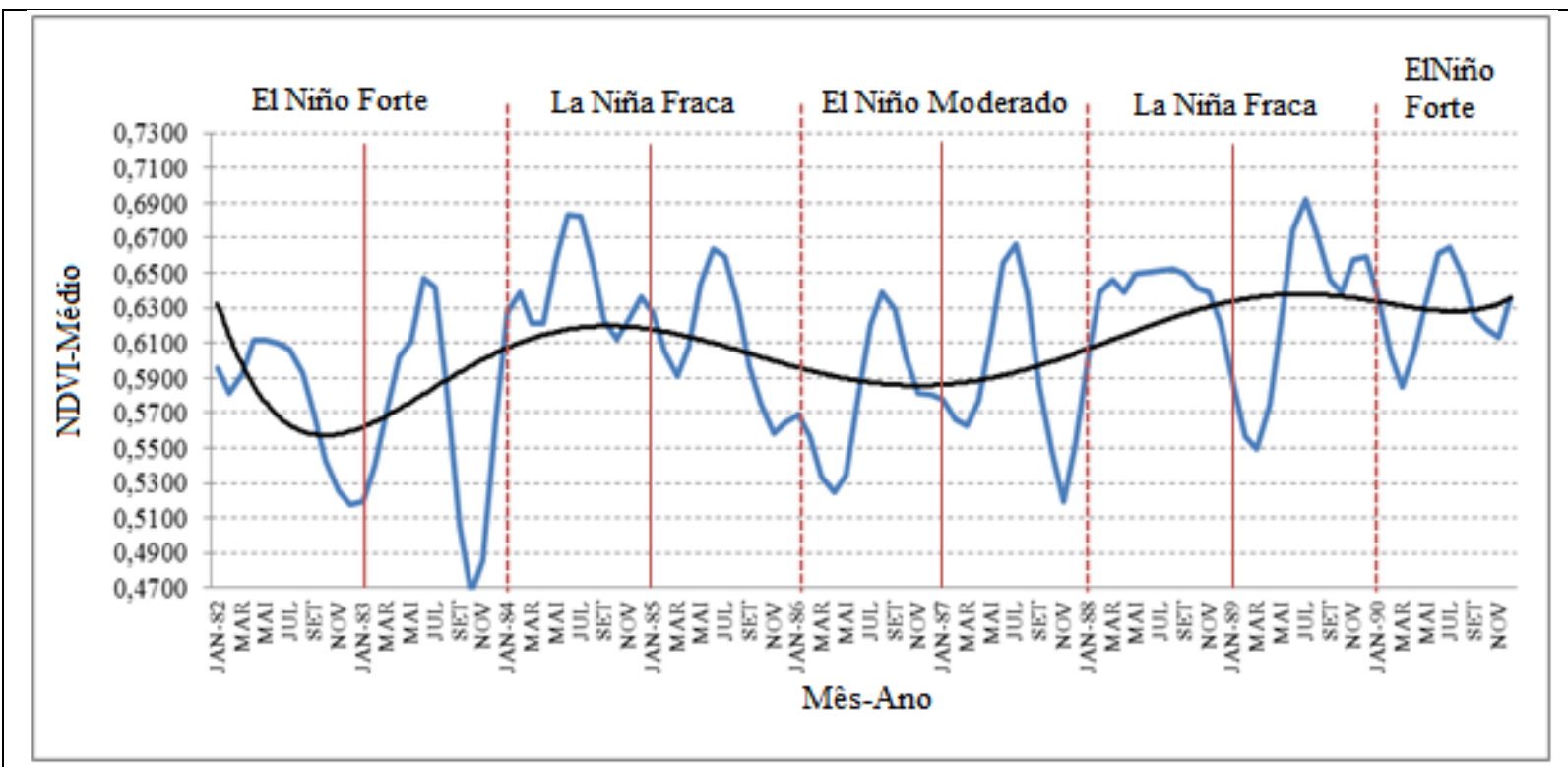

Figura 5 - NDVI médio para Manaus e eventos de El Niño e La Niña, para o periodo de 1982 a 1990.

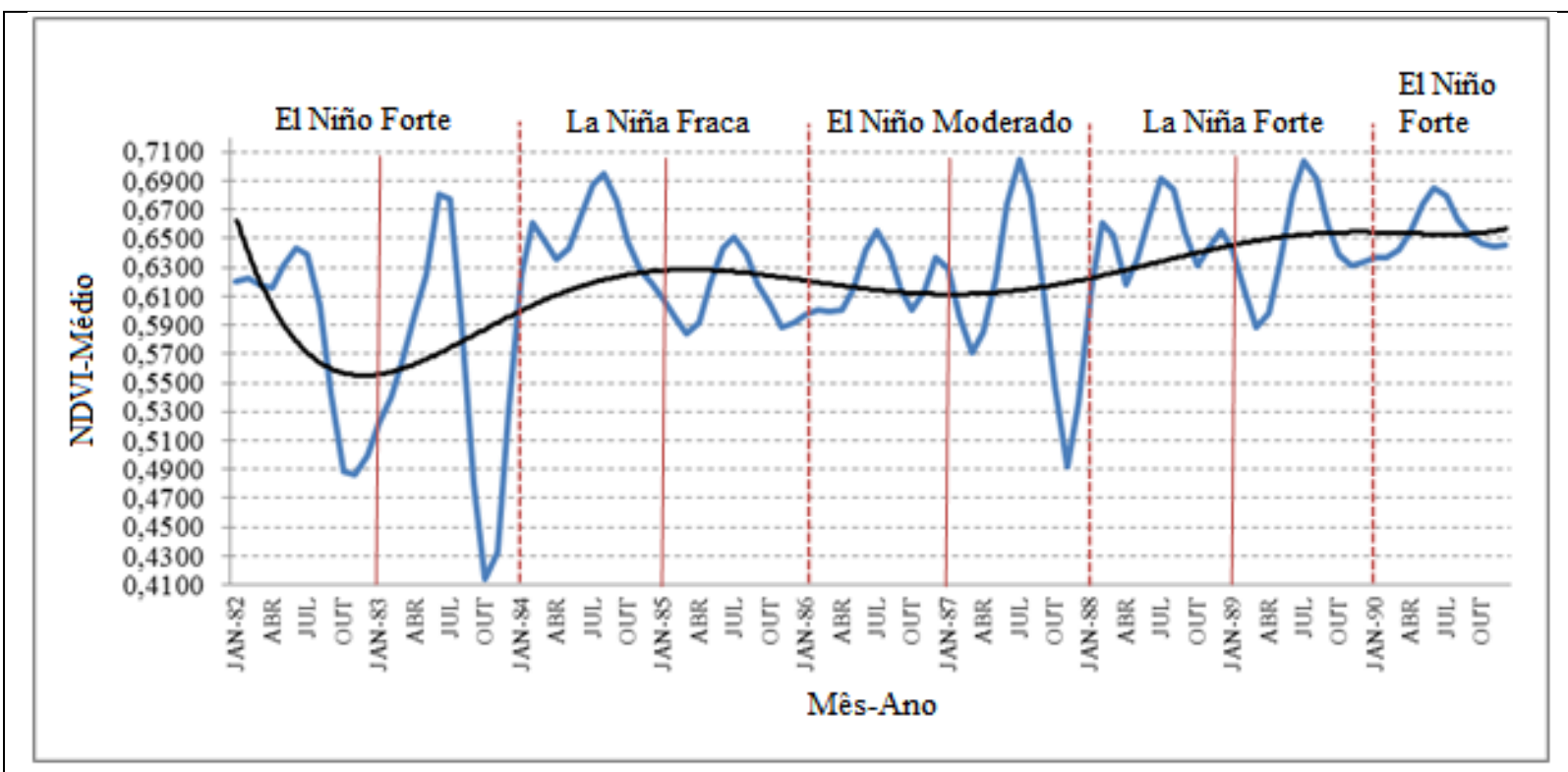

Figura 6 - NDVI médio para Parintins e eventos de El Niño e La Niña, para o periodo de 1982 a 1990. 


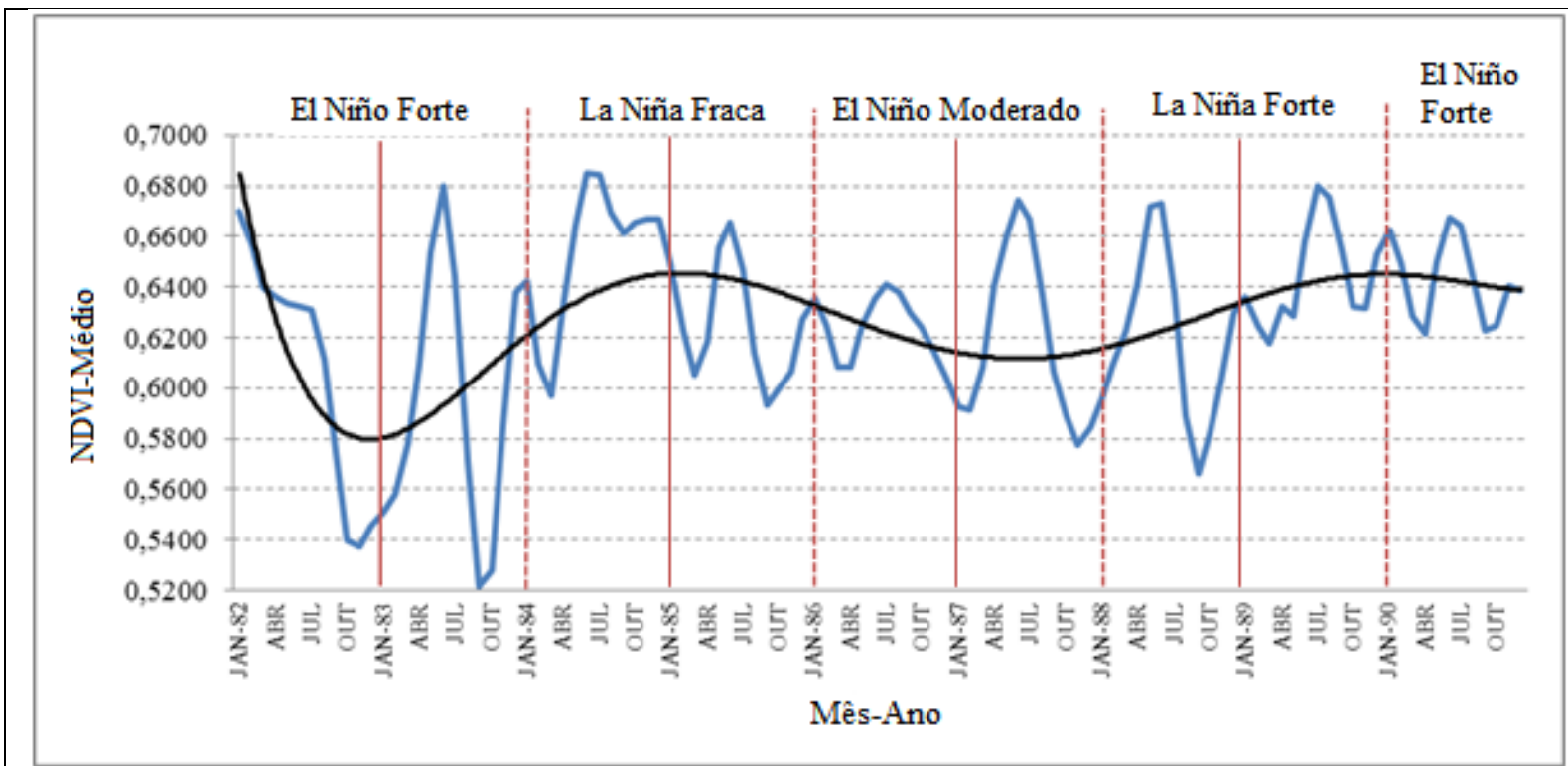

Figura 7 - NDVI médio para Tefé e eventos de El Niño e La Niña, para o periodo de 1982 a 1990 .

Tabela 4 - Valores anuais de deficiências hídricas para as cinco estações do INMET consideradas neste estudo e classe dos eventos de El Niño e La Niña

\begin{tabular}{|c|c|c|c|c|c|c|}
\hline \multirow[t]{2}{*}{ Ano } & \multicolumn{5}{|c|}{ Deficiência Hídrica Anual (mm) } & \multirow{2}{*}{ Classe do evento } \\
\hline & Barcelos & Itacoatiara & Manaus & Parintins & Tefé & \\
\hline 1982 & $-136,52$ & $-432,84$ & $-431,52$ & $-657,35$ & $-30,17$ & El Niño forte \\
\hline 1983 & $-252,09$ & $-98,72$ & $-171,74$ & $-836,36$ & $-128,35$ & El Niño forte \\
\hline 1984 & $-0,19$ & $-49,20$ & $-145,38$ & $-358,47$ & $-22,44$ & La Niña fraca \\
\hline 1985 & $-47,59$ & $-83,29$ & $-181,93$ & $-364,59$ & 0,00 & La Niña fraca \\
\hline 1986 & $-43,22$ & $-76,68$ & $-141,03$ & $-439,24$ & $-19,95$ & El Niño moderado \\
\hline 1987 & $-76,41$ & $-214,72$ & $-484,00$ & $-689,45$ & $-16,92$ & El Niño moderado \\
\hline 1988 & $-40,98$ & $-153,34$ & $-187,80$ & $-387,73$ & $-30,93$ & La Niña forte \\
\hline 1989 & $-42,58$ & $-83,83$ & $-79,14$ & $-308,86$ & $-34,41$ & La Niña forte \\
\hline Total (mm) & $-639,58$ & $-1192,62$ & $-1822,54$ & $-4042,05$ & $-283,17$ & \\
\hline
\end{tabular}

Os valores anuais de NDVI (Tabela 5) variaram da seguinte forma: Barcelos entre 7,33 - 7,90, com uma amplitude de 0,57 (7\%); Itacoatiara entre $6,77-7,75$, com uma amplitude de 0,97 (13\%); Manaus entre 6,74 7,68, com uma amplitude de 0,73 (10\%); Parintins entre $6,66-7,83$, com uma amplitude de 1,17 (15\%); Tefé entre 7,12 - 7,84, com uma amplitude de 0,72 (9\%). Os menores valores ocorreram todos em 1983, ano de El Niño forte. Por sua vez, os maiores valores ocorreram todos em 1984, ano de La Niña fraca. Para Manaus e Barcelos, os maiores valores se repetiram em 1988 e 1989, ambos anos de La Niña forte. A maior amplitude ocorreu em Parintins e a menor em Barcelos. 
Tabela 5 - Valores anuais de NDVI para as cinco estações do INMET consideradas neste estudo e classe dos eventos de El Niño e La Niña

\begin{tabular}{|c|c|c|c|c|c|c|}
\hline \multirow{2}{*}{ Ano } & \multicolumn{5}{|c|}{ NDVI Anual } & \multirow{2}{*}{ Classe do evento } \\
\hline & Barcelos & Itacoatiara & Manaus & Parintins & Tefé & \\
\hline 1982 & 7,56 & 6,94 & 6,96 & 7,01 & 7,31 & El Niño forte \\
\hline 1983 & 7,33 & 6,77 & 6,74 & 6,66 & 7,12 & El Niño forte \\
\hline 1984 & 7,90 & 7,75 & 7,68 & 7,83 & 7,84 & La Niña fraca \\
\hline 1985 & 7,87 & 7,36 & 7,33 & 7,33 & 7,50 & La Niña fraca \\
\hline 1986 & 7,61 & 7,07 & 6,95 & 7,42 & 7,49 & El Ninõ moderado \\
\hline 1987 & 7,69 & 7,20 & 7,07 & 7,25 & 7,43 & El Ninõ moderado \\
\hline 1988 & 7,79 & 7,67 & 7,68 & 7,81 & 7,42 & La Niña forte \\
\hline 1989 & 7,90 & 7,32 & 7,53 & 7,71 & 7,72 & La Niña forte \\
\hline Total & 61,65 & 58,08 & 57,93 & 59,02 & 59,83 & \\
\hline
\end{tabular}

A variação da deficiência hídrica total do período oscilou entre $-283,17 \mathrm{~mm}$ em Tefé e $-4042,05 \mathrm{~mm}$ em Parintins, com uma amplitude de $-3758,88 \mathrm{~mm}$ (93\%). Para o NDVI a variação ficou entre 57,93 em Manaus e 61,65 em Barcelos, apresentando uma amplitude de 3,72 (6\%). Isso indica que pequenas variações no NDVI podem representar grandes variações de deficiência hídrica nas condições fenológicas da vegetação estudada.

\section{Conclusões}

A análise anual evidenciou que as curvas do BHC e do NDVI apresentaram comportamentos semelhantes, indicando que a resposta do NDVI ao déficit/excedente hídrico ocorre com certa defasagem no tempo, sendo mais rápida a resposta em relação à deficiência hídrica do que ao excedente. Os menores valores de NDVI ocorreram após a estação seca e os maiores após a estação chuvosa. Vale ressaltar quem pequenas variações no NDVI podem representar grandes variações de deficiência hídrica nas condições fenológicas da vegetação.

A análise interanual demonstrou que em anos de El Niño, houve um decréscimo dos valores de NDVI e um acréscimo em anos de La Niña. Os maiores e menores valores de deficiências hídricas anuais foram encontrados em anos com evento de El Niño e La Niña, respectivamente. Os menores valores anuais de NDVI ocorreram em ano de El Niño forte e os maiores valores anuais em ano de La Niña fraca. O NDVI mostrou ser uma ferramenta útil, indicando (respondendo) de forma satisfatória as épocas de déficit e excedente hídrico para as regiões do estudo. O NDVI também se mostrou útil em indicar os efeitos dos eventos climáticos El Niño e La Niña na vegetação. Em períodos de El Niño houve um decréscimo no índice, revelando a influência do evento, por se tratar de um período seco na região, que resulta na diminuição do vigor da vegetação. Em períodos de La Niña houve um aumento no índice, revelando a influência do evento, por se tratar de um período chuvoso na região, que resulta no aumento do vigor da vegetação.

Recomenda-se para estudos futuros o uso de uma série de dados de NDVI com uma melhor resolução espacial, bem como uma série de dados que contemplem mais anos e que seja mais atual, afim de que possam ser mais bem quantificadas as influências dos eventos climáticos, tais como El Niño e La Niña. Entretanto, é de suma importância trabalhar com séries de dados cujos ruídos devido à influência da atmosfera e do sensor tenham sido filtrados. 


\section{Referências}

ALMEIDA, E.S. Relação entre índice de vegetação derivado do NOAA-AVHRR e precipitação na região amazônica. 1997. 109 f. Dissertação (Mestrado em Meteorologia) - Instituto Nacional de Pesquisas Espaciais, São José dos Campos.

ALMEIDA, E.S.; BATISTA, G.T. Índice de vegetação versus precipitação na Amazônia. In: SIMPÓSIO BRASILEIRO DE SENSORIAMENTO REMOTO, 9, 1998, Santos, SP. Anais do... Santos, 1998. Disponível em: http://marte.dpi.inpe.br. Acesso em: 28 fev. 2012.

ASSAD, E.D.; SETZER, A; MOREIRA, L. Estimativa da precipitação através dos índices de vegetação do satélite NOAA. In: SIMPÓSIO BRASILEIRO DE SENSORIAMENTO REMOTO, 5, 1988, Natal, RN. Anais do... Natal, 1988. Disponível em: http://marte.dpi.inpe.br. Acesso em: 28 fev. 2012.

ASSAD, E.D.; CASTRO, L.H.R.; ALMEIDA, S.A.O. Analise exploratória da variação espaço temporal do índice de vegetação NOAA/AVHRR e pluviometria: Caso dos cerrados brasileiros. In: SIMPÓSIO BRASILEIRO DE SENSORIAMENTO REMOTO, 8, 1996, Salvador, BH. Anais do... Salvador, 1996. Disponível em: http://marte.dpi.inpe.br. Acesso em: $28 \mathrm{fev}$. 2012.

BARBOSA, H.A. Análise espaço temporal de índice de vegetação AVHRR/NOAA e a precipitação na região nordeste do Brasil em 1982-85. 1998. 169 f. Dissertação (Mestrado em Meteorologia) - Instituto Nacional de Pesquisas Espaciais, São José dos Campos.

BATISTA, G.T.; SHIMABUKURO, Y.E; LAWRENCE, W.T. The long-term monitoring of vegetation cover in the Amazonian region of northern Brazil using NOAA-AVHRR data. International
Journal of Remote Sensing, v. 18, n.15, p. 3195-3210, 1997.

BORMAN, L.S.; NOBRE, C. Secas na Amazônia: causas e consequências. Oficina de Texto, 2013, 367p.

CAMPOS, I.B.P.; PAIVA, C.M, OLIVEIRA, L.M.T.; FRANÇA, G.B. Análise dos efeitos do déficit hídrico na resposta temporal do Índice de Vegetação por Diferença Normalizada (NDVI) em diferentes condições climáticas do estado do Rio de Janeiro. In: SIMPÓSIO BRASILEIRO DE SENSORIAMENTO REMOTO, 14, 2009, Natal, RN. Anais do... Natal, 2009.

FILHO, J.M. O Livro de ouro da Amazônia. Ediouro, 2006, 442p.

GUTMAN, G.G. Towards Monitoring Droughts from Space. Journal of Climate, v. 3, n.2, p. 282 - 295.

HELLDÉN, U.; EKLUNDH, L. National Drought Impact Monitoring- A NOAA NDVI and precipitation data study of Ethiopia. Lund Studies in Geography, Ser. C. General, Mathematical and Regional Geography, v.15, p. 1-55, 1998.

HUTCHINSON, C.F. Uses of satellite data for famine early warning in sub-Saharan Africa. International Journal of Remote Sensing, v.12, n. 6, p. 1405 - 1421, 1991.

IBGE. Mapa de Biomas do Brasil. 2004, 1p. Disponível em: ftp://geoftp.ibge.gov.br/. Acesso em: 25 set. 2011.

KOGAN, F.N. Remote sensing of weather impacts on vegetation in non-homogeneous áreas. International Journal of Remote Sensing, v.11, n.8, p. 1405-1419, 1990.

LIU, W.T.; KOGAN, F.N. Monitoring regional drought using the Vegetation Condition Index. International Journal of Remote Sensing, v.17, n. 14, p. 2761-2782, 1996. 
MORAN, E.F. Meio Ambiente \& Florestas. Senac, 2010, 224p.

MARENGO, J. A.; NOBRE, C.A.; CHOU, S.C.; TOMASELLA, J.; SAMPAIO, G.; ALVES, L.M.; OBREGÓN, G.O.; SOARES, W.R.; BETTS, R.; KAY, G. Riscos das Mudanças Climáticas no Brasil: Análise conjunta Brasil-Reino Unido sobre os impactos das mudanças climáticas e do desmatamento na Amazônia. Instituto Nacional de Pesquisas Espaciais (INPE), Met Office Hadley Centre (MOHC), 2011, 56p. Disponível em: http://www.inpe.br/noticias/arquivos/pdf/r elatorioport.pdf. Acesso em: 30 set. 2012.

NOBRE, C.A.; SAMPAIO, G.; SALAZAR, L. Mudanças Climáticas e Amazônia. Ciência e Cultura, v.59, n. 3, p. 22-27, 2007. Disponível em: http://cienciaecultura.bvs.br. Acesso em: 26 set. 2012.

OLIVEIRA, L.M.T. Estudo das regiões fitoecológicas brasileiras pela FAPAR/NDVI e relações com séries temporais de dados pluviométricos. 2008. 208 f. Tese (Doutorado em Engenharia Civil) - Instituto Alberto Luiz Coimbra de Pós - Graduação e Pesquisa de Engenharia, Universidade Federal do Rio de Janeiro, Rio de Janeiro.

PAIVA, C.M.; OLIVEIRA, L.M.T.; FRANÇA, G.B.; NICACIO, R.M. Análise dos efeitos do déficit hídrico na resposta temporal do Índice de Vegetação por Diferença Normalizada (NDVI) em diferentes condições climáticas do território brasileiro. In: CONGRESSO BRASILEIRO DE ENGENHARIA AGRÍCOLA, 36, 2007, Bonito, MS. Anais do... Bonito, 2007.

CAMPOS, I.B.P.; PAIVA, C.M, OLIVEIRA, L.M.T.; FRANÇA, G.B. Análise dos efeitos do déficit hídrico na resposta temporal do Índice de Vegetação por Diferença Normalizada (NDVI) em diferentes condições climáticas do estado do Rio de Janeiro. In: SIMPÓSIO BRASILEIRO DE
SENSORIAMENTO REMOTO, 14, 2009, Natal, RN. Anais do... Natal, 2009.

STÖCKLI, R.; VIDALE, P.L. European plant phenology and climate as seen in a 20-year AVHRR land-surface parameter dataset. International Journal of Remote Sensing, v.25, n. 17, p. 3303-3330, 2004. Disponível em: http://courses.washington.edu. Acesso em: 18 jan. 2012.

THORNTHWAITE, C.W.; MATHER, J. R. The water balance. Centerton, NJ: Drexel Institute of Technology, Laboratory of Climatology, 1995, 104p. 